\title{
ANÁLISE DA ESTRUTURA DE CAPITAL DE EMPRESAS COM GOVERNANÇA CORPORATIVA
}

\author{
COLLOCA, Flávia Rúbia ${ }^{1}$ \\ AMBROZINI, Marcelo Augusto ${ }^{2}$
}

Recebido em: 2009-06-20

Aprovado em: 2009-09-18

ISSUE DOI: $10.3738 / 1982.2278 .280$

RESUMO: O termo Governança Corporativa tornou-se comum a partir da década de 1990 entre as empresas, por se tratar de um conjunto de normas que leva as empresas a serem mais transparentes e dinâmicas com o mercado, procurando assim, captar sempre o maior número possível de novos investidores. A adoção de práticas de Governança Corporativa levanta a seguinte questão: se as empresas que as adotam possuem estrutura de capital diferente das que não adotam. O objetivo desta pesquisa é demonstrar se a forma de distribuição da Estrutura de Capital se altera com a adesão das empresas por melhores práticas de Governança Corporativa. Os testes estatísticos demonstraram que as variações na estrutura de capital das empresas que adotam medidas de Governanças Corporativas e das que não adotam, não são significativas para se afirmar que as medidas de Governança Corporativa têm influência sobre a distribuição da Estrutura de Capital.

Palavras-chave: Estrutura de Capital. Governança Corporativa. Capital Próprio.

SUMMARY: The term Corporate Governance became common to leaving of the decade of 1990 among the companies, for treating of a group of norms that takes the companies they be her more transparent and dynamics with the market, seeking like this, to always capture the largest possible number of new investors. The adoption of practices of Corporate Governance lifts the following subject: if the companies that adopt possess them capital structure different from the ones that they don't adopt. The objective of this research is to demonstrate the form of distribution of the Structure of Capital he/she loses temper with the adhesion of the companies for best practices of Corporate Governance. The statistical tests demonstrated that the variations in the structure of capital of the companies that you/they adopt measures of Corporate Governance and of the ones that they don't adopt, they are not significant to affirm that the measures of Corporate Governance have influence on the distribution of the Structure of Capital.

Keywords: Capital Structure. Corporate Governance. Own Capital.

\section{INTRODUÇÃO}

A abertura de capital é uma fonte alternativa de captação de recursos para a empresas e apresenta vantagens sobre os recursos ofertados pelas instituições financeiras. A abertura de capital ajuda o processo de captação de recursos, pois é um financiamento por meio de emissão de ações, com um custo menor aos praticados nos financiamentos bancários. Em contrapartida a empresa de capital aberto tem como obrigação e dever prestar informações ao mercado sobre seu desempenho.

\footnotetext{
${ }^{1}$ Bacharel em Administração.

${ }^{2}$ Mestre em Controladoria e Contabilidade. Prof. FFCL/FE.
} 
Uma empresa poderá financiar seus projetos através de seus recursos próprios que podem desenvolver-se pela retenção de seus resultados e, principalmente, pelo lançamento de ações ao público. A empresa que opta pelo lançamento de ações para captação de recursos atrai novos sócios que estão cada vez mais atentos ao comportamento da empresa e ao rendimento de seu capital investido, modificando dessa forma a maneira como as empresas disponibilizam seus resultados e a forma como os recursos financeiros são direcionados para financiar seu crescimento.

Justifica-se essa pesquisa baseada na forma como as empresas brasileiras captam recursos para financiar seus projetos, está mudando ao longo do tempo. As empresas saíram de uma gestão fechada e familiar para uma gestão aberta e profissional, ocasionada pela abertura de seu capital em bolsas de valores. O crescente interesse dos investidores por maiores retornos e menores riscos, fez com que as empresas adotassem medidas de governança que auxiliassem na transparência de sua gestão, dando assim, mais confiança aos investidores ao escolherem as ações onde investir. Através da gestão transparente supõe-se que seja mais fácil para as empresas captar mais recursos para o financiamento de seus projetos, possibilitando assim, seu crescimento e desenvolvimento.

A partir do estudo realizado, buscou-se explorar a forma como as empresas brasileiras de capital aberto constituem sua Estrutura de Capital antes e depois da criação dos modelos de Governança Corporativa. Procurou-se demonstrar se a Governança Corporativa influi na decisão de composição da Estrutura de Capital da empresas brasileiras de capital aberto.

Como problema da pesquisa tem-se: As empresas que adotaram medidas de Governança Corporativa possuem uma Estrutura de Capital diferente das que não adotaram?

O objetivo do presente trabalho foi demonstrar se as empresas que adotam práticas de Governança Corporativa possuem Estrutura de Capital diferente das empresas que não adotam. As empresas analisadas foram aquelas listadas na bolsa de valores com e sem níveis de governança corporativa, para que seja possível comparar se tais práticas ocasionam impacto na estrutura de capital.

\section{HIPÓTESE DE PESQUISA}

As empresas que adotaram medidas de Governança Corporativa possuem Estrutura de Capital diferente das que não adotaram. 


\section{HIPÓTESE NULA}

As empresas que adotaram medidas de Governança Corporativa não possuem Estrutura de Capital diferente das que não adotaram, ou seja, possuem uma estrutura de capital igual às das empresas que não adotaram práticas de governança corporativa.

\section{VARIÁVEIS}

As variáveis que serão utilizadas durante a análise dos dados, são os itens que influenciam diretamente na alteração da estrutura de capital da empresa. A estrutura de capital é a relação direta entre passivo oneroso e patrimônio líquido e as variáveis, que determinam essa alteração, são: empréstimos, financiamentos, debêntures, capital social e lucros acumulados.

As empresas utilizadas para a análise dos dados, foram 140 de capital aberto com níveis de governança corporativa e 125 sem níveis de governança, para se ter uma idéia clara se a governança corporativa afeta a estrutura de capital da empresa.

\section{ABERTURA DE CAPITAL}

No Brasil, o processo de abertura de capital traz vantagens adicionais determinadas principalmente por nosso cenário econômico de altas taxas de juros e restrições ao crédito de longo prazo. Basicamente, uma das fontes de financiamento de longo prazo com um custo financeiro competitivo para o tomador de recursos são as linhas de crédito oferecidas pelo BNDES. Taxas de juros livremente praticadas no mercado são mais elevadas que o retorno médio dos ativos das empresas nacionais, inviabilizando seu crescimento mediante uma estrutura de capital mais alavancada. A tabela 1 resume as principais vantagens e desvantagens da abertura de capital de uma empresa.

TABELA 1 - Vantagens e desvantagens da abertura de capital.

\begin{tabular}{l|l}
\hline \multicolumn{1}{c|}{ Vantagens } & \multicolumn{1}{c}{ Desvantagens } \\
\hline $\begin{array}{l}\text { Captação de recursos financeiros para } \\
\text { investimentos; }\end{array}$ & Distribuição obrigatória de dividendos; \\
$\begin{array}{l}\text { Prazo indeterminado para pagamento dos } \\
\text { recursos levantados; }\end{array}$ & $\begin{array}{l}\text { Levantamento e publicação periódica de } \\
\text { informações ao mercado; }\end{array}$ \\
$\begin{array}{l}\text { Obtenção de recursos a custos mais } \\
\text { baratos; }\end{array}$ & $\begin{array}{l}\text { Elevados custos com a criação de departamento } \\
\text { de relações com o mercado; }\end{array}$ \\
$\begin{array}{l}\text { Melhores condições de liquidez para os } \\
\text { acionistas }\end{array}$ & Há sempre a necessidade de novos investimentos; \\
$\begin{array}{l}\text { Reforça critérios de governança } \\
\text { corporativa }\end{array}$ & Necessidade de debater a estratégia publicamente. \\
\hline
\end{tabular}

Fonte: Pinheiro (2005) 


\section{GOVERNANÇA CORPORATIVA}

O termo governança corporativa foi criado no início da década de 1990 nos países desenvolvidos, para demonstrar as regras, que controlam o relacionamento dentro de uma companhia, entre os interesses de acionistas controladores, acionistas minoritários e administradores.

As práticas de Governança Corporativas no Brasil surgiram em resposta a necessidade de capitação de fontes de financiamento para a atividade empresarial. As empresas já mencionam boas práticas de governança corporativa em suas estratégias de negócio.

Conforme o $\operatorname{IBGC}^{3}(2008)$ :

Governança corporativa é o sistema pelo qual as sociedades são dirigidas e monitoradas envolvendo os relacionamentos entre Acionistas/Cotistas, Conselho de Administração, Diretoria, Auditoria Independente e Conselho fiscal. As boas práticas de governança corporativa têm a finalidade de aumentar o valor da sociedade facilitar seu acesso ao capital e contribuir para a sua perenidade.

De acordo com a Bovespa (2008):

Uma empresa que possui boas práticas de governança está estruturada de tal forma que a administração conduz os negócios considerando o interesse de todos os seus acionistas, sem distinção entre o acionista controlador e o acionista investidor. Esse equilíbrio proporcionará maior confiança ao investidor, caso se torne sócio da companhia, de que não terá os seus interesses prejudicados em benefício do acionista controlador, que, em última instância, é quem tem o poder de decisão sobre a gestão.

\section{GOVERNANÇA CORPORATIVA NO BRASIL}

A partir da década de 1990, com a abertura da economia brasileira, investidores estrangeiros começaram a participar em proporção cada vez maior no capital das empresas brasileiras. Mais ainda, essas companhias passaram a ter contato com práticas avançadas de relação com investidores, acionistas minoritários e analistas de mercado aplicadas no mercado americano, que obrigaram as empresas a aperfeiçoar suas políticas de divulgação de informações. A partir daí, as empresas brasileiras começaram a ter contato com acionistas mais exigentes e sofisticados, acostumados a investir em mercados com práticas de governança corporativa mais avançadas que as aplicadas no mercado brasileiro.

Ao número crescente de investidores estrangeiros soma-se uma maior participação de investidores institucionais brasileiros de grande porte e mais conscientes de seus direitos. Para reforçar ainda mais a tendência do aprimoramento das práticas de governança corporativa, o processo de privatização dos anos 90 resultou, em muitos casos, no surgimento de grandes empresas privatizadas cujo controle passou a ser compartilhado entre vários grupos nacionais 
e internacionais. Algumas iniciativas institucionais e governamentais foram implementadas nos últimos anos com o objetivo de assegurar a melhorias das práticas de governança corporativa das empresas brasileiras, das quais destaca-se a criação do Novo Mercado e dos Níveis 1 e 2 de governança corporativa pela Bolsa de Valores de São Paulo - Bovespa.

Governança corporativa relata o conjunto de processos, costumes, políticas, leis, regulamentos e instituições que regulam a maneira como uma empresa é dirigida, administrada ou controlada. O termo inclui também o estudo sobre as relações entre os diversos atores envolvidos, os stakeholders, e os objetivos pelos quais a empresa se orienta. Os principais atores tipicamente são os acionistas, a alta administração e o conselho de administração. Outros participantes da governança corporativa incluem os funcionários, fornecedores, clientes, bancos e outros credores, instituições reguladoras (como a CVM, o

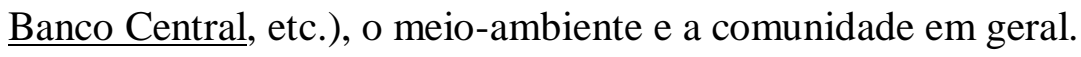

\section{NÍVEL 1 E NÍVEL 2 DE GOVERNANÇA CORPORATIVA}

Conforme a Bovespa (2008), existem níveis diferenciados de governança corporativa. Estes são divididos de acordo com os compromissos que a empresa assume com o mercado e seus investidores. Desse modo, classificam-se como companhias de Nível 1, Nível 2 e Novo Mercado.

Nível 1 e 2 - Trata-se de níveis diferenciados de governança corporativa. De acordo com a Bovespa (2008), quando uma empresa adere ao Nível 1 ou 2 assume um compromisso com o mercado e seus acionistas; este é formalizado através de um contrato firmado entre a Bovespa, a empresa, os administradores, o conselho fiscal e controladores. Ao assumir este compromisso, a empresa deve seguir o Regulamento de Listagem específica, estruturado de acordo com o segmento a que a empresa pertence, contendo as práticas a serem seguidas.

NÍVEL 1: As Companhias Nível 1 se comprometem, principalmente, com melhorias na prestação de informações ao mercado e com a dispersão acionária. As principais práticas agrupadas no Nível 1 são:

- Manutenção em circulação de uma parcela mínima de ações, representando $25 \%$ do capital;

- Realização de ofertas públicas de colocação de ações por meio de mecanismos que favoreçam a dispersão do capital;

- Melhoria nas informações prestadas trimestralmente, entre as quais a exigência de consolidação e de revisão especial; 
- Prestação de informações sobre negociações de ativos e derivativos de emissão da companhia por parte de acionistas controladores ou administradores da empresa;

- Disponibilização de um calendário anual de eventos corporativos;

- Apresentação das demonstrações do fluxo de caixa.

NÍVEL 2 Para a classificação como Companhia Nível 2, além da aceitação das obrigações contidas no Nível 1, a empresa e seus controladores adotam um conjunto bem mais amplo de práticas de governança e de direitos adicionais para os acionistas minoritários. Resumidamente, os critérios de listagem de Companhias Nível 2 são:

- Conselho de Administração com mínimo de cinco membros e mandato unificado de um ano;

- Disponibilização de balanço anual seguindo as normas do US GAAP ou IAS;

- Extensão para todos os acionistas detentores de ações ordinárias das mesmas condições obtidas pelos controladores quando da venda do controle da companhia e de, no mínimo, 70\% deste valor para os detentores de ações preferenciais;

- Direito de voto às ações preferenciais em algumas matérias, como transformação, incorporação, cisão e fusão da companhia e aprovação de contratos entre a companhia e empresas do mesmo grupo;

- Obrigatoriedade de realização de uma oferta de compra de todas as ações em circulação, pelo valor econômico, nas hipóteses de fechamento do capital ou cancelamento do registro de negociação neste Nível;

- Adesão à Câmara de Arbitragem para resolução de conflitos societários

\section{NOVO MERCADO}

Segundo Assaf Neto (2005), o Novo Mercado é um segmento especial da Bovespa em que são listadas para negociar ações de empresas que se comprometem, de forma voluntária, com a adoção de boas práticas de governança corporativa, maior transparência e qualidade na divulgação de informações aos acionistas (disclousure), e concordância em submissão de divergências e conflitos à Câmara Arbitragem de Mercado da Bovespa.” 
De acordo com a Bovespa (2008), o Novo Mercado é direcionado principalmente à listagem de empresas que venham a abrir o seu capital, enquanto os Níveis Diferenciados, Nível 1 e Nível 2, são direcionados para empresas que já possuem ações negociadas na BOVESPA.

No final dos anos 90 era evidente a crise de grandes proporções pela qual passava o mercado de ações no país. O número de companhias listadas na Bovespa tinha caído de 550 em 1996 para 440 em 2001. O volume negociado após atingir US\$ 191 bilhões em 1997, recuara para US\$ 101 bilhões em 2000 e US\$ 65 bilhões em 2001. Além disso, muitas companhias fechavam o capital e poucas abriam. É nesse cenário que a Bovespa, em mais uma das medidas tomadas com o objetivo de reanimar o mercado, cria o Novo Mercado como um segmento especial de listagem de ações de companhias que se comprometam voluntariamente a adotar as boas práticas de governança corporativa.

Numa necessária adaptação à realidade do mercado de ações brasileiro, são criados dois estágios intermediários: Níveis I e II, que juntos com o Novo Mercado estabelecem compromissos crescentes de adoção de melhores práticas de governança corporativa. A idéia que norteou a criação do Novo Mercado tem seu fundamento na constatação de que entre os diversos fatores que contribuem para a fragilidade do mercado de capitais brasileiro está a falta de proteção aos acionistas minoritários. Dessa forma, a valorização e a liquidez das ações de um mercado são influenciadas positivamente pelo grau de segurança que os direitos concedidos aos acionistas oferecem, e pela qualidade das informações prestadas pelas empresas.

A ausência de regras adequadas de defesa dos interesses dos acionistas minoritários acarreta a exigência por parte dos investidores de um deságio sobre o preço da ação, causando uma desvalorização no valor de mercado das companhias. Dessa forma, é esperado que as empresas cujas ações estejam listadas em algum dos segmentos diferenciados de governança corporativa, nas quais os riscos envolvidos são minimizados, apresentem prêmios de risco consideravelmente reduzidos, implicando valorização do patrimônio de todos os acionistas.

As principais características dos segmentos de negociação de empresas com boas práticas de governança no NOVO MERCADO são:

- Realização de ofertas públicas de colocação de ações por meio de mecanismos que favoreçam a dispersão do capital;

- Manutenção em circulação de uma parcela mínima de ações representando $25 \%$ do capital; 
- Extensão para todos os acionistas das mesmas condições obtidas pelos controladores quando da venda do controle da companhia;

- Conselho de Administração com mínimo de cinco membros e mandato unificado de um ano;

- Disponibilização de balanço anual seguindo as normas do US GAAP ou IAS;

- Introdução de melhorias nas informações prestadas trimestralmente, entre as quais a exigência de consolidação e de revisão especial;

- Obrigatoriedade de realização de uma oferta de compra de todas as ações em circulação, pelo valor econômico, nas hipóteses de fechamento do capital ou cancelamento do registro de negociação no Novo Mercado;

- Prestação de informações sobre negociações envolvendo ativos e derivativos de emissão da companhia por parte de acionistas controladores ou administradores da empresa;

- Apresentação das demonstrações de fluxo de caixa;

- Adesão à Câmara de Arbitragem do Mercado para resolução de conflitos societários.

O sucesso da iniciativa da Bovespa pode ser atestado pelo nível de adesão de empresas ao Novo Mercado e aos Níveis I e 2 de Governança, como comprova a seguinte relação de companhias listadas nesses mercados.

\section{ESTRUTURA DE CAPITAL}

A estrutura de capital é determinada pela composição de endividamento a longo prazo que uma empresa utiliza para financiar suas operações. As decisões inadequadas de estrutura de capital podem resultar em um elevado custo de capital, o qual tornaria mais difícil encontrar investimentos aceitáveis. As decisões empresariais procuram diminuir o custo de capital da empresa, tornando mais fácil achar investimentos aceitáveis que aumentarão a riqueza dos proprietários.

Outros fatores que afetam a Estrutura de Capital das empresas:

- Imposto de Renda da Pessoa Física: diferença de tratamento entre dividendos e ganhos de capital.

- Interferência Governamental: por afetar sua arrecadação de impostos. 
- Garantir Possibilidade de se Endividar: utilizar menor endividamento para garantir acesso a oportunidades de investimentos que vierem a surgir.

- Conflitos entre acionistas da empresa e assimetria informacional entre eles

- Empresa global e acesso a fontes mais baratas de capital

A questão fundamental em relação à estrutura de capital das empresas, é a relação ideal entre capital de terceiros e capital próprio que maximiza a riqueza dos acionistas. Segundo Modigliani ; Miller (1958), em seus primeiros estudos, uma empresa não é capaz de alterar o valor total de seus títulos mudando as proporções de sua estrutura de capital, o valor da empresa é sempre o mesmo qualquer que seja a estrutura de capital. Anos mais tarde de estudos Modigliani; Miller reescreveram sua teoria e alteraram suas proposições sobre o pensamento da estrutura de capital.

A primeira teoria desenvolvida por Modigliani; Miller é chamada de Proposição I de Modigliani; Miller, onde os autores afirmam que o valor de uma empresa independe de sua estrutura de capital. Seja ela formada por capital próprio ou de terceiros não ocorre alteração no valor da empresa. Segundo Assaf (2007) "Proposição I de Modigliani ; Miller: O valor da empresa alavancada é igual ao da empresa não alvancada."

Modigliani; Miller revisaram sua teoria e criaram a Proposição II, na qual, afirmaram que as empresas alvancadas (uso de capital de terceiros), possuem maior risco, portanto, exige para seus acionistas maior retorno, ou seja, segundos os autores, o retorno esperado de uma ação está positivamente relacionado ao grau de endividamento, pois o risco para o acionista cresce com o endividamento.

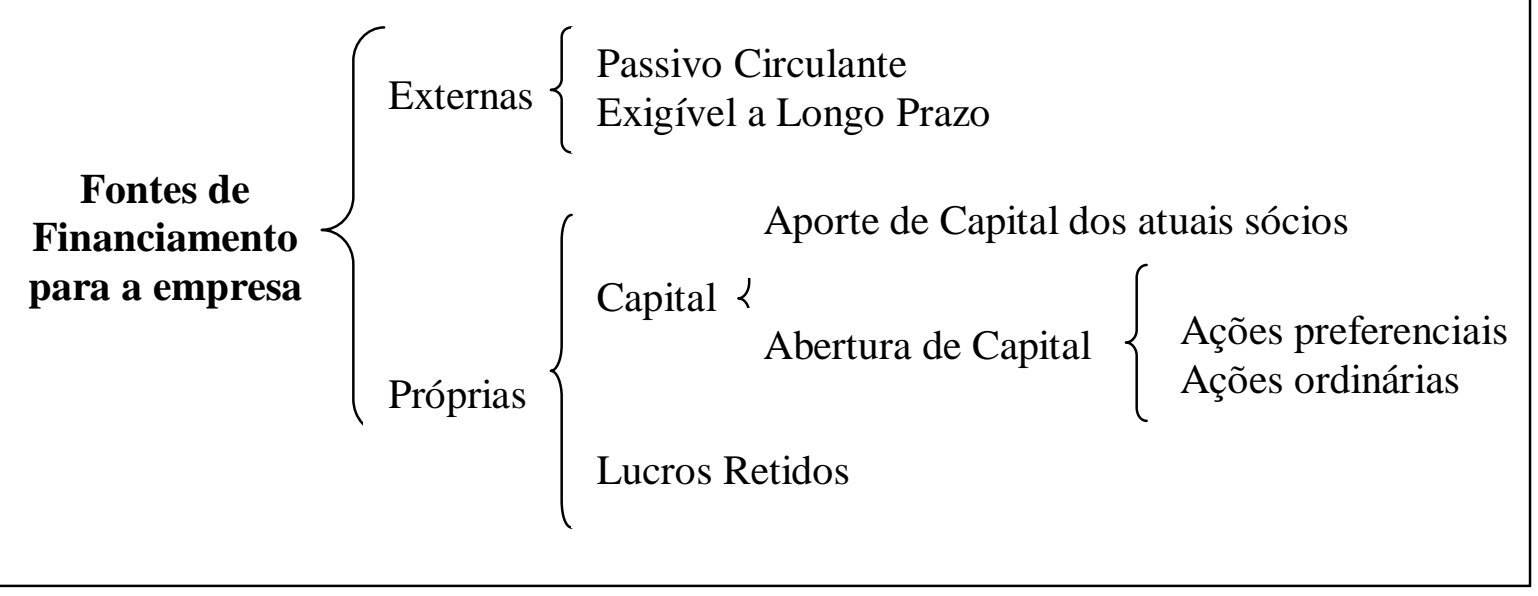

FIGURA 1 - Fontes de financiamento para a empresa.

Fonte: Pinheiro (2005) 
Encontram-se muitos debates na literatura financeira, procurando definir se existe uma estrutura "ótima" de capital. Os que acreditam na existência de uma estrutura "ótima" de capital são partidários da assim chamada abordagem tradicional, e os que discordam, são considerados defensores da abordagem Modigliani; Miller. Não se aprofundará nesse assunto, pois o objetivo deste artigo não é demonstrar se existe ou não uma estrutura ótima de capital e sim demonstrar os efeitos que os níveis de Governança Corporativa causam na Estrutura de Capital das Empresas.

Casarotto Filho (1996) alega que os investimentos da organização deverão render o suficiente para pagar os juros dos capitais de terceiros e proporcionar um lucro compatível com as expectativas dos acionistas. Afirma ainda que os recursos para investimento provêm de várias fontes: recursos próprios, empréstimos e debêntures, todos devendo ser remunerados seja através dos lucros ou dos juros. Investidores e proprietários das organizações buscam ser recompensados pelo custo da oportunidade de investirem seus capitais em um empreendimento em relação a qualquer outro empreendimento ou forma de investimento de risco equivalente.

Para Gitman (2001), em finanças corporativas as decisões estratégicas de primeira importância estão concentradas em três frentes de análise e estruturação: investimentos, financiamentos e dividendos. Para fazer frente à necessidades de capital para financiar seus negócios, as organizações possuem duas alternativas: utilizar-se de capitais próprios e/ou de capitais de terceiros. A decisão de escolher a combinação das fontes de financiamento da organização é conhecida como a decisão de estrutura de capital.

A questão da estrutura de capital é considerada extremamente complexa. Quanto às micro, pequenas e médias organizações, tal complexidade tende a ser maior, visto que as mesmas têm pouca acessibilidade ao crédito e as informações contábeis geradas não são bastante confiáveis aos olhos dos investidores e financiadores. Além disso, a pouca diversificação encontrada nas atividades destas organizações eleva o risco de exploração e retorno de capitais, inibindo a atração de investidores e dificultando o acesso destas organizações ao mercado de capitais.

Segundo Braga (1989), nas decisões sobre estrutura de capital, a dúvida constante é: o que leva uma organização a escolher uma certa fonte de capital? A resposta que apresenta maior ocorrência e utilização é a que vincula o uso do capital ao seu custo, apontando a literatura financeira o custo do capital próprio e do capital de terceiros como variáveis muito importantes em finanças corporativas, tendo papel central em grande parte das decisões financeiras, por ser um padrão de referência e ligação entre as decisões de investimento e financiamento. 
De acordo com Vieira (2005) se o financiamento gera custos, o retorno ajustado ao risco dos projetos nos quais tal financiamento é empregado deve ser tal que gere caixa suficiente para que assim: a) pague aos credores o principal e os juros devidos; b) pague aos acionistas o custo do capital próprio e c) apresente um lucro excedente que seja responsável pelo incremento da riqueza desses acionistas.

\section{REVISÃO DA LITERATURA}

Fama; Grava (2000), afirmam que Modigliani; Miller entraram em contradição quando desconsideraram o ganho fiscal das empresas como determinante do valor da empresa em 1958 e incluíram-no novamente em 1963, para depois negá-lo em 1977. Para os autores, as conclusões de M; M feriram o mundo dos negócios quando concluíram em 1963 que o valor da empresa deveria ser crescente com seu endividamento. O ponto de vista defendido por Fama; Grava (2000) é de que uma dívida grande traz problemas e não valor adicional.

Segundo Barros, Fama; Silveira (2001), Modigliani; Miller propunham que, sob certas condições, a estrutura de capital das empresas era irrelevante para agregar seu valor $\mathrm{M} ; \mathrm{M}$ foram os pioneiros nas realização de testes empíricos, onde os resultados confirmaram a hipótese de irrelevância. No trabalho realizado por Barros, Fama e Silveira (2001), os testes de $\mathrm{M}$; $\mathrm{M}$ foram reaplicados com dados atuais de empresas latino-americanas e norteamericanas e apresentaram diferenças em relação à pesquisa original de $\mathrm{M} ; \mathrm{M}$.

Perobelli ; Famá (2002) concordam que de acordo com a teoria de finanças, a emissão de dívidas é muito mais viável para certos tipos de empresas do que a emissão de ações. Utilizando essa lógica, os autores afirmam que se a empresa assumir novas dívidas para financiar um projeto, pode ser interpretado pelo mercado como um sinal de que a taxa de retorno do projeto será superior aos juros cobrados pelos credores, elevando o valor da empresa. Em contrapartida a emissão de novas ações para financiar seus projetos, poderia ser interpretada pelo mercado como um sinal negativo, onde a taxa de retorno exigida pelo projeto não foi suficiente, justificando assim a necessidade da emissão de mais ações. Com base em seus estudos os autores procuraram também verificar no mercado brasileiro, quais seriam os fatores que induzem o endividamento das empresas, e a partir daí, traçar o perfil da empresa para a qual o endividamento não se apresenta como uma alternativa viável.

Aguiar, Corrar; Batistella (2004), analisaram em seu trabalho os impactos causados sobre três variáveis (quantidade média, volume médio em Reais e preço médio de ações) no desempenho das ações das empresas depois da implementação do nível 1 de governança corporativa, tendo em vista que a expectativa por parte da BOVESPA era de que essas 
variáveis sofressem aumento ou valorização significativa depois da migração das empresas. Observou-se porém, que não houveram mudanças significativas com a migração para o Nível de 1 Governança Corporativa, não correspondendo com a expectativa da Bovespa.

Silva (2004), analisou os efeitos da estrutura de controle e propriedade no valor de mercado, na estrutura de capital e na política de distribuição de dividendos no Brasil. Seu estudo diz que existe uma relação, muitas vezes estatisticamente significativa, entre estrutura de governança, valor de mercado, alavancagem e política de dividendos das empresas brasileiras.

Nakamura, Martin; Kayo (2004), desenvolveram um modelo para a determinação na prática da Estrutura ótima de Capital, baseado no pressuposto de que os administradores buscam se aproveitar do máximo de benefícios das economias fiscais decorrentes do uso das dívidas, preservando um nível mínimo de capital próprio que assegure a situação de solvência patrimonial da empresa. Baseados em Modigliani; Miller (1958) os autores assumiram a idéia de que o custo de capital da empresa é afetado pelo nível de risco dos ativos operacionais e não pela forma como a estrutura de capital é desenhada.

No trabalho realizado por Santos (2006), observou-se que os fatores que determinam a estrutura de capital das empresas não é mais o oportunismo, e sim a adoção de uma estrutura meta. Os motivos apontados pelas empresas para não utilizar o mercado de capitais são a excessiva burocracia e o alto custo operacional. Em contrapartida foram apresentados os fatores de valorização da empresa e a visibilidade no mercado financeiro, como sendo os responsáveis pela utilização do mercado de capitais pelas empresas.

Segundo Mazer (2007), a diminuição do custo de capital das empresas, acontece por meio de um maior nível de transparência, a divulgação de informações é apoiada pela literatura em duas correntes teóricas. A primeira afirma que uma maior transparência aumenta a liquidez das ações no mercado , portanto a demanda por seus títulos aumenta, reduzindo assim o custo de capital das empresas, e a segunda corrente de pensamento sugere que maior transparência pode reduzir o custo de capital, pela redução do risco não diversificável.

\section{MATERIAL E MÉTODO}

As empresas escolhidas para realizar a presente pesquisa, foram 140 empresas de capital aberto, listadas na Bolsa de Valores no Novo Mercado e Níveis I e II de Governança Corporativa, e 125 empresas de capital aberto listadas na bolsa de valores sem níveis de governança corporativa. Estas empresas estão disponibilizadas no site da Bovespa com acesso Nucleus, v.6, n.2. out.2009 
rápido e gratuito. Os testes estatísticos procuraram demonstrar se os níveis de governança corporativa afetaram a estrutura de capital das empresas em suas variáveis: empréstimos, financiamentos, debêntures, capital social e lucros acumulados. Os teste estatísticos foram rodados no programa Statdisk1 que foi desenvolvido por Triola (2005) e que está disponível em seu livro.

\section{ANÁLISE DOS RESULTADOS}

A pesquisa realizada para a elaboração deste artigo foi através de um levantamento com os nomes das empresas de capital aberto, listadas na bolsa de valores nos nível de governança corporativa, denominados de Novo Mercado, Nível 1 e Nível 2. A pesquisa não foi influenciada por impressões pessoais e nenhuma de suas variáveis foi modificada.

A análise estatística realizada, tenta estabelecer se os resultados obtidos têm significância estatística, de acordo com limites preestabelecidos. Existem muitos e diferentes testes estatísticos, que podem ser empregados de acordo com o tipo de variáveis estudadas, que dependem do tipo do estudo, que por sua vez depende da pergunta da pesquisa.

Para testar estatisticamente as hipóteses levantadas nesse estudo, utilizou-se a metodologia de inferência sobre duas médias para amostras independentes descrita por Triola (2005). Todas as exigências necessárias para esse teste foram satisfeitas, a saber: a) as duas amostras são independentes; e b) os dois tamanhos amostrais são ambos grandes, ou seja, maiores que trinta.

Com base no índice de endividamento das empresas da amostra desse estudo, determinou-se primeiramente o tamanho da amostra, depois calculou-se a média e o desvio padrão dos índices de endividamento das empresas e, por fim, rodou-se o teste estatístico no software Statdisk® que foi desenvolvido por Triola (2005).

A figura 2 mostra os resultados do teste sobre duas médias para amostras independentes. 


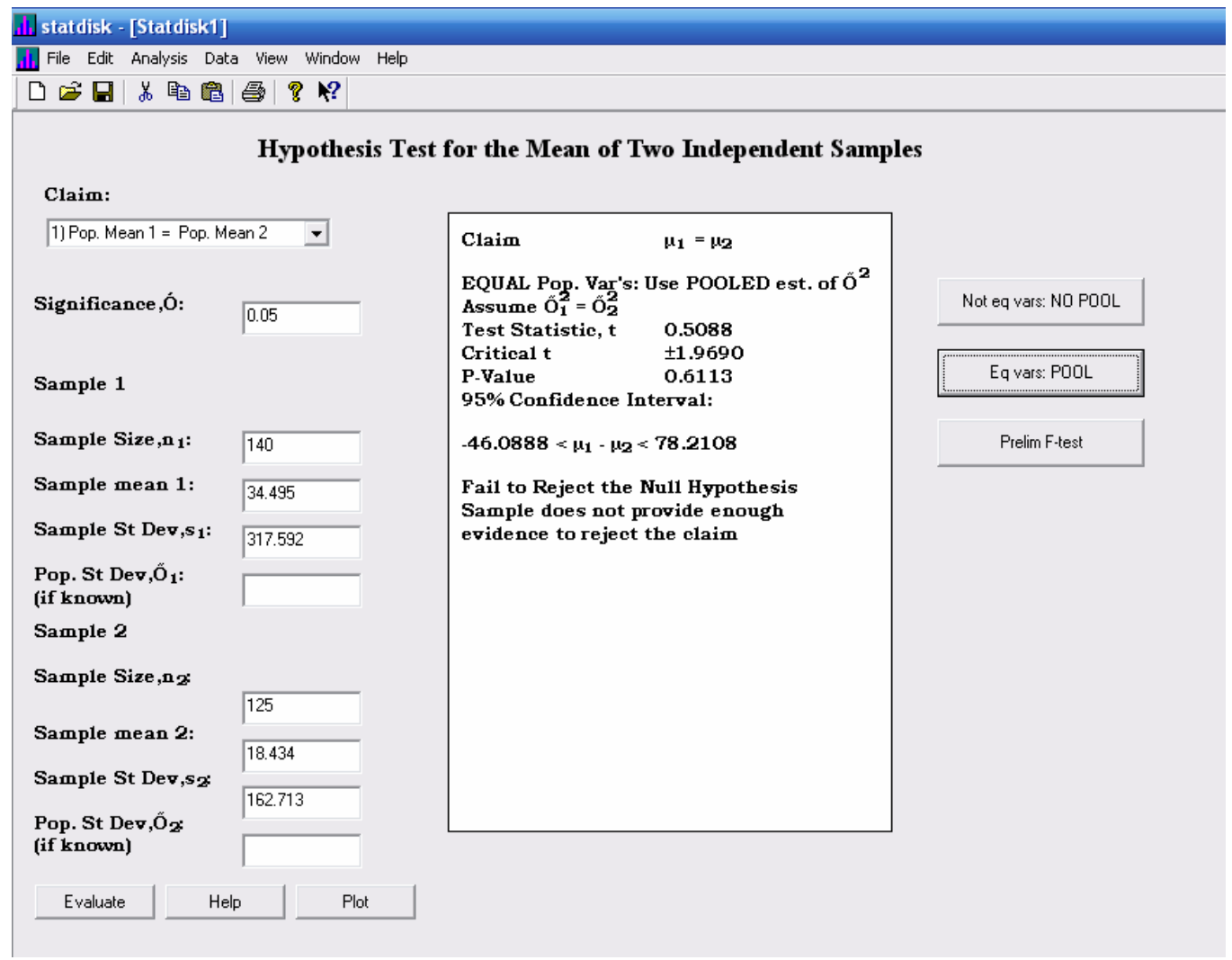

FIGURA 2 - Resultado do teste de hipóteses

Como pode ser observado na figura 2, a hipótese de estudo (claim) é a de que a média da população 1 (neste caso, o endividamento das empresas brasileiras com governança corporativa) é igual à média da população 2 (neste caso, o endividamento das empresas brasileiras que não possuem práticas de governança corporativa). O grau de significância é de 0.05, o que representa um nível de confiança de 95\%. O tamanho da amostra 1 é de 140 empresas. A média de endividamento da amostra é de 34,495 e o desvio-padrão da amostra 1 é de 317,592. Com relação aos dados das empresas brasileiras que não possuem práticas de governança corporativa, o tamanho da amostra 2 é de 125 empresas, a média do índice de endividamento da amostra 2 é de 18,434 e o desvio-padrão da amostra 2 é de 162,713.

Conforme observado na figura 2 , os dados inputados no software estatístico apresentaram falha ao rejeitar a hipótese nula (fail to reject the null hypotesis). Ou seja, a hipótese de nulidade $\left(\mathrm{H}_{0}\right)$ deste estudo de que "o nível endividamento das empresas brasileiras que adotam práticas de governança corporativa não é diferente ao nível endividamento das empresas brasileiras que não adotam práticas de governança corporativa" não pode ser rejeitada (deve ser aceita). Isso significa que há evidências empíricas suficientes para permitir 
que se afirme que o nível endividamento das empresas brasileiras que adotam práticas de governança corporativa é igual daquelas que não adotam tais práticas, sendo essa diferença estatisticamente significativa.

\section{CONSIDERAÇÕES FINAIS}

O objetivo da pesquisa foi demonstrar se os níveis de governança corporativa afetam ou não a estrutura de capital de uma empresa. A pesquisa se limitou a analisar as empresas que já possuíam níveis de governança corporativa com as que não possuíam, sem separação de setores de atuação. Porém, para um futuro trabalho, há a possibilidade de comparar as empresas por setor de atuação e também compará-las com o antes e o depois da implantação dos níveis de governança corporativa, o que tornaria a pesquisa mais complexa e abrangente, dentre os vários fatores que afetam a Estrutura de capital de uma empresa, esta pesquisa se limitou a analisar apenas um que é a Governança Corporativa.

As empresas aqui utilizadas para elaboração desta pesquisa não incluíram os Bancos, apesar de os mesmos estarem enquadrados nos níveis de governança corporativa, porém possuem uma legislação específica para elaboração de sua estrutura de capital que segue as regras do acordo da Basiléia ${ }^{4}$.

Foram utilizadas um total de 265 empresas como amostra para realização da pesquisa, das quais 140 estão classificadas nos níveis de governança corporativa e 125 não têm classificação em níveis de governança corporativa.

Com a utilização do software estatístico StatDisk foi possível comparar os índices de endividamento das duas hipóteses (empresas com e sem níveis de governança corporativa) e verificou-se que o nível endividamento das empresas brasileiras que adotam práticas de governança corporativa é estatisticamente igual ao o nível endividamento das empresas brasileiras que não adotam essas práticas, ou seja, a governança corporativa é capaz de alterar a estrutura de capital das empresas aqui analisadas.

A intenção deste estudo, foi realmente verificar se os níveis de governança corporativa possuíam alguma relação com a estrutura de capital, não aprofundando se essa relação é benéfica ou não para as empresas. Esta pode ser uma questão para ser estudada em futuros

\footnotetext{
${ }^{4}$ Este acordo define o mínimo necessário de capital (patrimônio dos acionistas) que os bancos tem que reservar para fazer frente às perdas inesperadas decorrentes dos riscos de mercado e crédito. O capital reservado tem que ser de, no mínimo, $8 \%$ do volume de ativos ponderados da instituição financeira.
} 
trabalhos sobre os benefícios de se ter uma estrutura de capital mais alavancada que outra e retomar a antigas questões sobre uma estrutura ótima de capital.

\section{REFERÊNCIAS}

AGUIAR, A. B.; CORRAR, L. J.; BATISTELLA, F. D. Adoção de práticas de governança corporativa e o comportamento das ações na Bovespa: evidências empíricas. Revista de Administração, São Paulo, v.39, n.4, p.338-347, out/nov/dez. 2004

ASSAF, A. N. Finanças corporativas e valor. São Paulo: Atlas, 2007. 716p.

ASSAF, A. N. Mercado financeiro. São Paulo: Atlas, 2005. 348p.

BRAGA, R. Fundamentos e técnicas de administração financeira. São Paulo: Atlas, 1989

CASAROTTO FILHO, N.; KOPITTKE, B. H. Análise de investimentos. São Paulo: Atlas, 1996

FAMA, R; GRAVA, J. W. Teoria da estrutura de capital: as discussões persistem, Caderno de pesquisa em administração, São Paulo, v.1, n.11, $1^{\circ}$ tim./2000.

FAMA, R.; BARROS, L.A. de C.; SILVEIRA, A.Di M. A estrutura de capital é relevante? novas evidências a partir de dados norte-americanos e latino-americanos. Caderno de Pesquisas em Administração. São Paulo, v.08, n. 2, abr./jun. 2001.

GITMAN, L. J. Princípios da administração financeira. São Paulo: Harbra, 2001

LAMEIRA, V. J. Mercado de capitais, Rio de Janeiro: Forense Universitária, 2003. 250p.

MAZER, L. P. O impacto do nível de transparência no custo do capital próprio das empresas do Ibovespa. Ribeirão Preto, 2007.

NAKAMURA, W. T.; MARTIN, D. M. L.; KAYO, E. K. Proposta para a determinação da estrutura de capital ótima, na prática. Revista de Administração. UNISAL, ano 01, n. 01, Americana - jun./dez. 2004.

PEROBELLI, F. F. C; FAMA, R. Determinantes de estrutura de capital: aplicação a empresas de capital aberto brasileiras. Revista de administração, São Paulo, v.37, n.3, p. 33-46, jun/set 2002.

PINHEIRO, J.L.P. Mercado de capitais: fundamentos e técnicas. 3. ed. São Paulo: Atlas, 2005.

ROSS, S. A; WESTERFIELD, R. W; JAFFE J. F. Administração financeira, São Paulo: Atlas, 2007. 500p. 
ROSS, S. A.; WESTERFIEL, R.; JORDAN, B. D. Princípios de administração financeira. Trad. Antonio Zoratto Sanvicente. 2 ed. São Paulo: Atlas, 1997.

SANTOS, C. M. Levantamento dos fatores determinantes da estrutura de capital das empresas brasileiras. 2006, 122p. Dissertação (Mestrado). Ribeirão Preto.

SILVA, A. L. C. Governança corporativa, valor, alavancagem e polítiva de dividendos das empresas brasileiras. Revista de Administração, São Paulo, v.39, n.4 p.348-361, out/nov/dez. 2004.

TRIOLA, M. F. Introdução à estatística. 9 ed. Rio de Janeiro: LTC, 2005.

VIEIRA, M. V. Administração estratégica do capital de giro. São Paulo: Atlas, 2005. 
